\title{
LOS REFERENTES TEÓRICOS, LITERARIOS Y ESTÉTICOS DE LA ÉPICA DIECIOCHESCA EN EL CORREO DE SEVILLA (1806): A PROPÓSITO DE LA LECTURA DE VIRGILIO, TASSO Y MILTON ${ }^{1}$
}

\author{
Theoretical, Literary and Æsthethic References to Enlightened \\ Epic in the Correo de Sevilla (1806): about Virgil, Tasso \\ and Milton Reading
}

\author{
Claudia GARCÍA-MINGUILLÁN \\ IEMYRhd-Universidad de Salamanca/Université de Poitiers \\ cgmt@usal.es
}

Fecha de recepción: 05/03/2019

Fecha de aceptación definitiva: 01/07/2020

RESUMEN: En este artículo se estudian los referentes teóricos, literarios y estéticos de la épica culta por medio de la publicación en el Correo de Sevilla (1806) de una comparación entre Virgilio y Tasso, además de una curiosa biografía de Milton. Como consecuencia de la lectura de la obra de Juan Andrés Origen, progresos y estado actual de toda la literatura (1784-1806), se publicaron dos artículos en este periódico, uno de ellos obra de Manuel María de Arjona. En él analiza el estilo de Virgilio y Tasso y pone de manifiesto la importancia de mantener la épica como género literario a través de una lectura emocional que parta del conocimiento de las normas teóricas.

1. Este trabajo se inscribe en el marco del grupo de investigación reconocido Estudios de literatura y pensamiento (ELYP) y del proyecto de investigación Teoría de la lectura y bermenéutica literaria en la Ilustración: edición de fuentes documentales y literarias (1750-1808) (FFI2016-80168-P) del Ministerio de Economía y Competitividad, con sede en el Instituto de Estudios Medievales y Renacentistas y de Humanidades Digitales (IEMYRhd) de la Universidad de Salamanca. 
Palabras clave: épica; siglo XVIII; lectura; estética; Virgilio; Tasso; Milton.

ABSTRACT: This paper studies the theoretical, literary and æesthetic references in the epic poetry published in the journal Correo de Sevilla (1806), where it appeared a comparison between Virgil and Tasso, besides a curious biography of John Milton. As a consequence of reading Juan Andrés' masterpiece Origen, progresos y estado actual de toda la literatura (1784-1806), two articles were published, one of them by Manuel María de Arjona. He analyzes Virgil and Tasso's style and reveals the matter of keeping epic poetry as a literary genre through an emotional reading following the theorical rules.

Key words: epic; 18th century; reading; aesthetic; Virgil; Tasso; Milton.

\section{INTRODUCCIÓN}

En 1789 se publicaba póstumamente la obra Cartas marruecas de José Cadalso. En la correspondencia entre los personajes de Nuño y Gazel, aquel afirma: "Alguna vez me he puesto a considerar cuán digno asunto para un poema épico es la venida de Felipe V a España, cuánto adorno se podría sacar de los lances que le acaecieron en su reinado; cuánto pronóstico feliz para España la amable descendencia que dejó» ${ }^{2}$. Diserta acerca del poema épico, especialmente en sus aspectos formales; extensión, rima, naturaleza del héroe, composición de la fábula y otras especificaciones técnicas para alcanzar la conclusión de que la épica es «el ave fénix de quien todos hablan y a quien nadie ha visto» ${ }^{3}$. En la prensa dieciochesca la épica ocupó algunas páginas, no muchas si se tiene en cuenta el espacio dedicado a otros géneros de mayor aclamación como el teatro o la novela. Tal es el caso del Memorial literario instructivo y curioso de la Corte de Madrid (1784-1808), periódico que más menciones a la épica recoge, concretamente a partir de 1785. Le siguen el Espiritu de los mejores diarios literarios que se publican en Europa (1787-1791, 1795) y el Diario de Madrid (1781-1808). Estas noticias, que bien pueden ser consideradas como crítica literaria, parten del fundamento del debate de ideas literarias en las discusiones en torno al canon ${ }^{4}$ y las normas de composición,

2. CADAlso, José. Cartas marruecas. Ed. Jesús Cañas Murillo. Madrid: Academia del Hispanismo, 2016, p. 325.

3. Cadalso. Op. cit. 2016, p. 325.

4. Para profundizar en la construcción del canon entre los siglos XVIII y XIX, se debe consultar RODRÍGUEZ SÁNCHEZ DE LEÓn, María José. "La pugna entre antiguos y modernos en el periodo de entre siglos: del canon y lo clásico». En GaviÑo Rodríguez, Victoriano y Durán López, Fernando (eds.). Gramática, canon e historia literaria. Estudios de filología española entre 1750 y 1850 . Madrid: Visor Libros, 2010, pp. 373-396 y ARADRA SÁNCHEZ, Rosa María. «El canon en la literatura española (siglos XVIII y XIX)». En POZuelo Yvancos, José María y ARAdra SÁnchez, Rosa María. Teoría del canon y literatura española. Madrid: Cátedra, 2000, pp. 143-303. 
un espacio donde surgen noticias que ofrecen reflexiones y comparaciones entre autores clásicos a la vez que disertaciones sobre aspectos de su obra.

En Espíritu de los mejores diarios literarios que se publican en Europa, periódico bajo el amparo del conde de Floridablanca, se da a conocer una "Disertación sobre el poema épico, con motivo del Paraíso perdido de Milton" y pocos meses después un "Ensayo sobre Torquato Tasso». En el debate sobre la épica quinientista italiana le sigue el Diario de Madrid donde se publica un "Paralelo del Tasso y del Ariosto». El carácter de estas publicaciones roza lo erudito5. El conocimiento de las obras de preceptiva se refleja en la nómina de teóricos citados, que versa desde las autoridades de la escuela clásica, con el liderazgo de Boileau, hasta la contrapartida de Ludovico Muratori, siempre amparados en el neoclasicismo del siglo. Frente al discurso de autoridad emitido por preceptistas marcados por una dialéctica teórica, el estilo discursivo de un periódico generaba un texto más accesible que cualquier tratado de poética y retórica. Este proceso de "democratización» de la crítica literaria corresponde al vínculo estrechado por la prensa entre la sociedad y los sabios, tal y como proclamó Francisco Antonio de Escartín en el Correo literario de la Europa ${ }^{6}$. Junto a estos periódicos madrileños, la épica también fue objeto de atención en el Correo de Sevilla en el año de 18067. En este último se trata la épica en dos ocasiones; una, para dar noticia de la vida de Milton, autor del Paraíso Perdido ${ }^{8}$, y, otra, la publicación de una carta comparativa entre Virgilio

5. Estas no son más que un eco de la agitada presencia que gozó Tasso a lo largo del siglo XVII, momentos en los que se situó en la cúspide del gusto épico. Véase MARNi, Archimede. "Tasso in France in the seventeenth century". Allegory in the French Heroic Poem of the Seventeenth Century. Princeton: University Press, 1936, pp. 32-45.

6. Apud URZAINQUi, Inmaculada. "Un nuevo instrumento cultural: la prensa periódica». En ÁlvaREz BARrientos, Joaquín; López, François y URZAinqui, Inmaculada. La República de las Letras en la España del siglo XVIII. Madrid: Consejo Superior de Investigaciones Científicas, 1995, p. 130.

7. En la extensa bibliografía sobre la prensa dieciochesca literaria, consúltese LE GENTIL, Georges. Les revues littéraires de l'Espagne pendant la première moitié du XIXe siècle. Aperçu bibliographique. Paris: Hachette, 1909; CASTAÑón, Jesús. La crítica literaria en la prensa española del siglo XVIII (1700-1750). Madrid: Taurus, 1973; amén de los indispensables trabajos de UrZAINQUi, Inmaculada. "La crítica literaria en la prensa del siglo XVIII, elementos de su discurso teórico». Bulletin hispanique, 2000, 102, 2, pp. 519-559; "La república periodística al filo del 800». En MorALes MoyA, Antonio (coord.). 1802, España entre dos siglos. Madrid: Sociedad Estatal de Conmemoraciones Culturales, 2003, pp. 321-350, inter alia. Para conocer su dimensión sociológica consúltese RAABE, Paul. «Die Zeitschrift als Medium der Aufklärung». Wolfenbüttler Studien zur Aufklärung, 1974, I, pp. 99-112; ENCISO RECIO, Luis M. «Prensa y opinión pública». En Historia de España por Ramón Menéndez Pidal, tomo XXIX. Madrid: Espasa Calpe, 1985, pp. 195-258.

8. Publicado en Londres, en el año de 1667, captó el gusto de los intelectuales que un siglo después habitaban Sevilla. En esa ciudad, alrededor de 1778, Jovellanos tradujo el primer libro del Paraíso. La transmisión del texto en las letras españolas convive entre la traducción parcial y la traslación a la poesía propia para finalmente ser publicado en 1814 en la imprenta de Ibarra, con la traducción de Benito Ramón de Hermida. Sobre la traducción e influencia de Milton en el siglo XviII español, acúdase a Pegenaute, Luis. "La recepción de Milton en la España ilustrada: visiones de El Paraíso Perdido". En La traducción en España (1750-1830): lengua, literatura, cultura. Lleida: Universitat de Lleida, 1999, 
y Tasso realizada por Manuel María de Arjona y motivada tras la lectura de la obra de Juan Andrés, Origen, progresos y estado actual de toda literatura (edición original 1782-1799, edición española 1784-1806). Los tres autores -Virgilio, Tasso y Milton- son los ejes de referencia del género épico, junto a la figura de Homero. El Correo de Sevilla será el medio en el que se publiquen las noticias de mayor interés, tanto en cuanto su contenido sobresale entre los discursos canónicos de menor innovación discursiva publicados hasta esa fecha en la prensa mencionada.

La primera edición del Correo se publicó a comienzos del mes de octubre de 1803. Su fundación vino impulsada desde el ámbito más culto y erudito de las letras sevillanas. Dirigido por Justino Matute y Gavidia, contaba con los nombres estandartes de la escuela poética sevillana. Alberto Lista y Aragón, José María Blanco White, Francisco de Paula o Manuel María del Mármol, entre otros muchos, son los principales censores y redactores. El Correo contaba, por tanto, con una selecta nómina de poetas y académicos de la Real Academia Sevillana de Buenas Letras y la Real Academia de Letras Humanas. Este hecho contribuyó a que el contenido del periódico mostrase una concepción orgánica de la cultura, con el objetivo de, según reza el prospecto a la primera edición, "difundir las luces y fijar el gusto». Su carácter erudito se manifiesta en la concepción crítica e histórica de la literatura que recogen los discursos y noticias publicados. Ejemplo de ello es el concepto de épica que observamos en 1806, año en el que aparecen las noticias sobre la vida de Milton y una carta crítica de comparación entre Virgilio y Tasso. La pervivencia de este tipo de noticias, que rozan el rasgo de tópico, y su publicación en un medio como el Correo de Sevilla son una prueba del interés que la reflexión sobre los autores antiguos y modernos suscitaba entre sus académicos autores al igual que reflejan también su deseo por trasladarlo a sus lectores. Así, la teoría de un género en proceso de desaparición se publica como un acto divulgativo. Los clásicos épicos son presentados como grandes muestras literarias, que quien escribe, a su vez, conoce, lee, cita y recuerda, lo que hace que debata como crítico y, a la vez, como lector lo que el género y sus autores más eminentes le sugieren. Las noticias sobre Virgilio, Tasso y Milton destacan por la relación entre el Correo y las dos academias sevillanas, relación fundamental pues, como declaró Alberto Lista cuando finalizó en 1803 la actividad de la Academia de Letras Humanas, la Academia «murió, pero murió como cae la flor, dejando el fruto que le sobrevive»? La prensa recogió el testigo ocupándose, entre otros temas, del género épico.

pp. 321-334 y Torralbo Caballero, Juan de Dios. "La recepción de Milton en España: el papel del humanismo ilustrado sevillano». Alfinge, 2008, 20, pp. 151-170.

9. Aguilar PIÑal, Francisco. La Real Academia Sevillana de Buenas Letras en el siglo XVIII. Sevilla: Colegio Oficial de Aparejadores y Arquitectos técnicos de Sevilla, 2001, p. 26. 


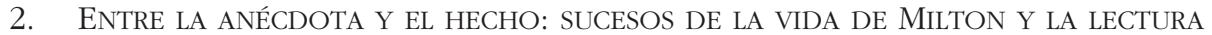 DE ViRgilio Y TASSO}

La primera referencia a la épica o, más exactamente, a los autores de épica, aparecida en el Correo de Sevilla es la titulada "Noticia de Milton, famoso poeta inglés» ${ }^{10}$. Este breve artículo, presentado sin firma de autor, constituye una defensa sostenida en tópicos sobre Milton que una vez más justifica la equiparación con Homero en tanto que autor épico por excelencia: «Milton con razón permanecerá siendo la gloria y admiración de Inglaterra y siempre se le comparará a Homero» ${ }^{11}$. El texto es también una defensa del Paraíso perdido (1667) como poema sujeto a la ortodoxia poética de la epopeya. Frente a la técnica compositiva de Milton, Dante representa lo contrario pues se le recrimina el uso de la imaginación "aún más caprichosa y extravagante». La crítica a los desvaríos imaginativos de los autores épicos italianos resulta un lugar común, e incluso tópico, en el desarrollo de la preceptiva.

En cuanto a la recepción española de Milton y su poema, Frank Pierce matiza que no es "a singular fact ${ }^{12}$ el éxito de El Paraíso Perdido en España. El aprecio autóctono hacia el poema sacro, género en el que las letras hispanas han aportado grandes textos, y la valoración crítica de la "poeticidad del cristianismo" ${ }^{13}$ ofrecían un entorno de buena recepción. Y no se quedaba solo en eso, sino que incitó muchas obras inspiradas en la pérdida del espacio y época ideal del hombre. El primer contacto que tuvo España con el Paraíso de Milton fue a través de una traducción en fragmentos que realizó Luzán ${ }^{14}$, también Jovellanos probó la pluma para traducir el poema sacro ${ }^{15}$. La trayectoria de Milton en España sobrepasa los ejercicios de traducción y transcurre entre reescrituras, como el poema La caída de Luzbel (1784) de Menéndez Valdés, y certámenes académicos para emular a Milton, como el convocado en 1799 bajo el reclamo La inocencia perdida por la Real Academia de Buenas Letras de Sevilla. Félix José Reinoso y Alberto Lista y Aragón, ambos miembros de las academias, participaron en este concurso, resultando el primero vencedor ${ }^{16}$. El destacado interés por Milton en la cuna intelectual

10. Correo de Sevilla, del sábado 4 de octubre de 1806, n. ${ }^{\circ} 315$, pp. 9-12.

11. Correo de Sevilla, del sábado 4 de octubre de 1806, n. ${ }^{\circ} 315$, p. 11.

12. PIERCE, Frank. "The canto épico of the Seventeenth and Eighteenth Centuries». Hispanic Review, 1947, 15, p. 32.

13. El debate sobre el valor poético de la materia cristiana ha sido estudiado por CHECA BELTRÁN, José. «Sobre la virtualidad estética de la materia cristiana: Quintana y Blanco White». En HeRnáNDEZ Guerrero, José Antonio et al. (eds.). Retórica, Literatura y Periodismo. Actas del V Seminario Emilio Castelar. Cádiz: Universidad de Cádiz, 2006, pp. 113-122.

14. Peers, E. Allison. "Milton in Spain». Studies in Philology, 1926, 23, p. 170.

15. Torralbo Caballero, Juan de Dios. "Jovellanos: traductor de poesía inglesa en Andalucía». Hikma, 2017, 16, pp. 112-131.

16. PiERCE, Frank. "The canto épico of the Seventeenth and Eighteenth Centuries». Hispanic Review, 1947, 15, p. 33. Torralbo Caballero, Juan de Dios. "Lista, Reinoso y Jovellanos: pioneros en la 
de la Sevilla dieciochesca resultó del debate sobre el empleo de la maquinaria divina pagana en contraposición de la cristiana y viceversa, incitado en España por una marcada religiosidad. Este tema desató una conocida polémica entre Quintana, Reinoso y José María Blanco, recogida en el periódico Variedades de ciencias, literatura y arte (1804-1805), a la vez que perteneció al debate secular producido en torno al género épico y sus nuevas formas ${ }^{17}$.

Destacábamos al principio la singularidad de las noticias aparecidas en el Correo de Sevilla, pues la razón de ser de la noticia coincide en las curiosidades y anécdotas que se conocían sobre la vida de Milton, más que por su interés literario. Tras la breve comparación con Homero y Dante, le siguen noticias de sus tres tortuosos matrimonios, relatados con reminiscencias de misoginia lúdica. Este relato no coincide con las vidas de Milton conocidas hasta el momento. En el Diccionario histórico abreviado de Jean Baptiste Ladvocat se presenta un perfil de Milton austero, sereno, grave: «se retiró a una pequeña casa en Holbrun, donde continuó su estudio", "vivió licenciosamente", "se mantuvo en su casa con mucha tranquilidad, no obstante que jamás escritor alguno había insultado tanto las testas coronadas» $^{18}$, perfil de hombre político y literato, destacan y alaban su vida tranquila, a pesar de la turbulenta participación política. En contraste con esta versión de la vida de Milton, las noticias del Correo informan de sucesos de la vida personal del poeta. Por ejemplo, una discusión política entre su mujer y él al ser de bandos políticos opuestos, realista frente al republicano. Le sigue el relato de una conversación de Milton con un amigo. A este, sorprendido por encontrar al poeta casado aun siendo ciego, responde Milton: "Os engañáis, pues no me faltaba más que ser sordo para ser el mejor marido del mundo”. Añaden a la narración un elogio de Lord Buckghan ${ }^{19}$ a la mujer de Milton. El poeta responde a la felicitación por tener una mujer "como una rosa": "Amigo, eso no lo veo yo, pero infiero que será una rosa por las espinas que tengo que sufrir». Por último, se describe una graciosa escena del poeta con sus tres hijas que, tras varios intentos por enseñarles lenguas clásicas, añade, ante su torpeza o desinterés: «Una lengua tenía bastante una mujer para hacerse temer». Estos son sucesos novelescos, exagerados y pseudoficticios

importación de poesía inglesa». En Blanco, María Pilar (ed.). El Cid y la Guerra de la Independencia: dos bitos en la bistoria de la traducción y la literatura. Madrid: Universidad Complutense, 2010, pp. 257-287.

17. La elección sobre la máquina divina fue uno de los aspectos medulares en las ideas teóricas de la épica. Sea como tópico o como elemento a partir del cual se podía elaborar un juicio complejo sobre la estructura del poema, es un aspecto que siempre ha estado presente. De este debate surge la obra de Pierre Valentin Faydit Remarques sur Virgile et sur Homere, et sur le stile poetique de l'Ecriture-Sainte (1705).

18. LADVOCAT, Jean Baptiste. Diccionario histórico abreviado. Madrid: imprenta de Joseph Rico, tomo IV, 1754, pp. 289-292.

19. Consideramos una posible confusión o errata en el nombre pues bien puede tratarse de George Villiers, II duque de Buckingham (1628-1687), debido a no ser solo político, sino también escritor, pudo codearse con Milton en el grupo de autores que conformaron la literatura de la Restauración (1660-1689). 
acerca de la vida de Milton, pues aparecen de manera intermitente y sin una versión oficial -en lo único que coinciden todas es en la ceguera de Milton, posible emulación a Homero-, aunque la aparecida en el Correo supone la más lúdica hasta ahora encontrada ${ }^{20}$. Asimismo, estas noticias cumplen la función de reclamo para humanizar al autor ${ }^{21}$, elemento para congeniar con el vulgus profanum del que clamaba alejarse Horacio. Este acercamiento más humano y trivial a la vida de los autores épicos se repite en la lectura comparativa de Virgilio y Tasso.

Al margen de estas frivolidades en torno a Milton, la siguiente publicación relacionada con el género épico es la titulada "Carta sobre la comparación entre Virgilio y el Tasso» ${ }^{22}$, publicada apenas una semana después que la vida del poeta inglés. En ella, el autor, cuya firma -D.M.M.de A.- revela el deseo de anonimato a veces mantenido en la prensa ${ }^{23}$, plantea una discusión literaria entre la poética clásica y la reflexión de un lector culto y cualificado ${ }^{24}$, conocedor del género y de

20. La vida de Milton generaba especial interés entre los lectores. Prueba de ello es el gran espacio que ocupa a nivel anecdótico la vida del poeta en las obras dedicadas al estudio de su obra. La consulta de biografías de Milton indica que eran anécdotas conocidas por todos, aunque no existe una versión única y con carácter oficial. Ver Johnson, Samuel. "The Lives of the Most Eminent English Poets". En The Works of Samuel Johnson. London, vol. II, 1787, pp. 82-176; MilTon, John. English poems edited with life, introduction and selected notes by R.C. Browne. Oxford: Clarendon Press, 1878; DANIELSON, Dennis (ed.). The Cambridge Companion to Milton. Cambridge: Cambridge University Press, 1999. Todavía en 1875 la edición al Paraíso de Cayetano Rusell añade una vida del poeta de varias páginas.

21. Es lícito dudar entre la humanización o vulgarización de la vida de Milton. Griffin discute si Paradise Lost supuso, contra todo pronóstico, "the seeds of mock-epic", salvando las debidas distancias con Alessandro Tassoni y La Secchia rapita (1622). Con todo, esta corriente de épica burlesca pudo haber afectado a la concepción que de la vida de los autores se tenía. GRIFFIN, Dustin. "Milton and the Decline of Epic in the Eighteenth Century». New Literary History, 1982, vol. 14, n. ${ }^{\circ}$ 1, pp. 143-154.

22. "Carta sobre la comparación entre Virgilio y el Tasso". Correo de Sevilla, del miércoles 15 de octubre de 1806, n. ${ }^{\circ}$ 318, pp. 33-36. Las comparaciones entre los autores más conocidos del género son habituales desde la publicación del poema de Tasso. Así, Paolo Beni publica en 1607 Comparatione di Homero, Virgilio e Torquato e a chi di loro si debba la Palma o Considerazioni al Tasso de Galileo. Para ahondar en el sistema literario en el que se sostienen estos discursos comparativos acúdase, principalmente, a VEGA, María José y VILÀ, Lara (dirs.). La teoría de la épica en el siglo XVI (España, Francia, Italia y Portugal). Vigo: Academia del Hispanismo, 2010. Además, la repercusión del binomio Ariosto-Tasso en la península ha sido estudiada en distintos espacios. Para mantener la línea de análisis y limitarnos a su influencia, nos limitaremos a citar TANGanelli, Paolo (ed.). La tela de Ariosto. El "Furioso» en España: traducción y recepción. Málaga: Universidad de Málaga, 2009; LARA GARRIDO, José. Los mejores plectros. Teoría y práctica de la épica culta en el Siglo de Oro. Málaga: Universidad de Málaga, 1999.

23. Como ha señalado Urzainqui: "La identidad de los periodistas se revela muy pocas veces a los lectores; probablemente, en la mayor parte de los casos, para preservar su personalidad y conducirse con mayor libertad de movimientos», URZAINQUI, Inmaculada. "Un nuevo instrumento cultural: la prensa periódica». En Álvarez BARrientos, Joaquín; López, François y UrZAINQUi, Inmaculada. La República de las Letras en la España del siglo XVIII. Madrid: Consejo Superior de Investigaciones Científicas, 1995, p. 177.

24. Esta combinación de saberes y procedimientos se observa en Juan Andrés quien, como ha señalado Rodríguez Sánchez de León, "procura ser el investigador empírico y el lector cualificado". RODRÍGuEz SÁNCHEZ DE LEÓN, María José. «El conocimiento científico y la comprensión hermenéutica 
las obras y autores más representativos. Podemos afirmar que el autor de la carta es Manuel María de Arjona ${ }^{25}$, conocido académico y literato del contexto sevillano de fin de siglo. No obstante, aun siendo publicada bajo el título de "Carta", originalmente es un discurso leído en la Academia de Letras Humanas el 23 de diciembre de $1798^{26}$. En ella demuestra ser conocedor de la tradición crítica del género épico. La motivación de la carta, como indica el autor, es declarar su opinión sobre los dos autores tomando como referente crítico el juicio de Juan Andrés en su paralelo entre la Eneida y la Jerusalén liberada ${ }^{27}$. Arjona discute esos mismos elementos para justificar su elección personal por el autor moderno.

La carta se divide en dos partes. En primer lugar, plantea un repaso de los tópicos de la poética tradicional sobre el género épico, en el que diserta sobre la acción, el estilo sublime, la caracterización de los héroes y el espacio de los poemas. En segundo lugar, reflexiona sobre la experiencia estética de la lectura personal del autor, aspectos explicados por medio de la sensibilidad lectora ${ }^{28}$. Este hecho genera una discusión abierta con el lector ajeno a los preceptos de la teoría dedicada a la épica, que puede, no obstante, aportar novedades interpretativas a partir de su lectura emocional. La fórmula de la carta contribuye a la separación de las disciplinas de la crítica literaria y la estética ${ }^{29}$, ya percibida en los autores italianos como Giambattista Vico y Ludovico Muratori.

En esa línea, la carta se sitúa en la tendencia comparativa del siglo tras el surgimiento de la querella entre los antiguos y los modernos. Este debate dirigió parte de su atención a la épica, conocida dentro del movimiento la "querella contra

y crítica de la literatura: la propuesta de Juan Andrés». En RodRíGuEz SánCHEZ DE LEÓn, María José y AMOres Fúster, Miguel (eds.). La ciencia literaria en tiempos de Juan Andrés (1740-1817). Madrid: Visor Libros, 2019, pp. 125-149.

25. Manuel María Arjona y de Cubas (1771-1820), académico supernumerario de la Real Academia Sevillana de Buenas Letras desde el 1 de junio de 1792, un año después de Juan Pablo Forner (Aguilar PiÑal. Op. cit., 2001, p. 314). En ella mantiene contacto con los miembros de la reconocida escuela poética de Sevilla, quienes desarrollaron su actividad entre dicha academia y la de Letras Humanas. El Correo de Sevilla supondrá un medio donde se publiquen los resultados de este grupo de intelectuales. Encontramos publicada bajo la autoría de la misma firma acronímica, "Plan para una historia filosófica de la poesía española, por D.M.M. de A.", publicada originalmente en el Correo de Sevilla y publicada de nuevo por Minerva o El Revisor general, n. ${ }^{\circ}$ LXVII, 1806. Sobre la vida y actividad de Arjona consúltese Biblioteca de autores españoles. Poetas líricos del siglo XVIII, tomo II. Madrid: Rivadeneyra, 1871, pp. 499-504.

26. Así lo confirma NAveros SÁnchez, Juan. El fundador de la Real Academia de Córdoba: D. Manuel María de Arjona y Cubas, 1771-1820. Córdoba: Real Academia de Ciencias, Bellas Letras y Nobles Artes de Córdoba, 1991, p. 174.

27. ANDRÉs, Juan. Origen, progresos y estado actual de toda la literatura, tomo III. Madrid: Sancha, 1785, pp. 280-281.

28. Álvarez Barrientos ha señalado la aparición de afectos o de la sensibilidad. Vid. Álvarez Barrientos, Joaquín. La novela del siglo XVIII. Madrid: ediciones Júcar, 1991, pp. 161-162; 372.

29. Para los caminos hacia la estética y la crítica literaria en autores italianos desde Vico hasta Juan Andrés, véase Romani, Bruno. La critica letteraria tra l'otto e il novecento. Roma: Gremese Editore, 1975, pp. 1-23. 
Homero" ${ }^{30}$, siendo un verdadero enfrentamiento discursivo entre los partidarios de Perrault y los miembros de la escuela liderada por Boileau, defensores de los autores clásicos. Lejos de quedar en un mero debate, la naturaleza de la querelle -y, en extensión, todo fenómeno cultural del siglo- debe identificarse en un profundo cambio epistemológico del pensamiento ${ }^{31}$. Los nuevos caminos del pensamiento ilustrado ofrecen la posibilidad de que el autor clásico no sea siempre reconocido como superior y, en este caso, la voz de autoridad de Juan Andrés se decanta por Tasso frente a Virgilio ${ }^{32}$. Recuperar este debate permite al autor de la carta plasmar su propia reflexión sobre la acción de la Jerusalén frente a aquella de la Eneida. Es importante tener muy presente que la época de publicación, mitad del primer decenio del inicio del nuevo siglo, avista el paso de la reflexión teórica a la exaltación de los autores nacionales. Si en esta carta el debate es la valoración de Tasso con Virgilio, es precisamente con el objetivo de preparar el discurso para ofrecer un poema español a la altura de Tasso. El italiano, previamente reconocido como autor del canon, aumenta su distancia con la época clásica y será un elemento equiparable entre los elementos del campo literario moderno.

Manuel María Arjona, antes de comenzar con el análisis, afirma: "Yo aseguro a vd. con franqueza que mi opinión será un poco particular y tal vez parecerá a vd. mismo demasiado favorable al Tasso». Esta valoración se reconoce como una práctica común en la Academia de Letras Humanas ${ }^{33}$. En 1799, un año después del discurso de Arjona, Lista y Aragón lee el discurso Examen a Balbuena, que encaja

30. Debates que abarcaban asuntos de crítica literaria donde la traducción de Homero presenció un acalorado enfrentamiento entre Anne Dacier (1645-1720) y Houdar La Motte, contra quien Dacier compuso su ensayo Des causes de la corruption du goût (Paris, 1714).

31. Cambio progresivamente asimilado con el método cartesiano, la irrupción del dominio de la razón y la fluctuación entre pensamiento deductivo e inductivo. La filosofía inglesa de principios de siglo, especialmente el sensismo de Locke y el inductivismo, generó, junto a Newton, el camino hacia una nueva ciencia que, con impacto en todo campo de conocimiento, incluidas las bellas artes, indujo una novedad en el método del pensamiento. Sebold habla de "influencia liberalizadora" de Locke en la relación de la teoría literaria y Luzán. Sobre la irrupción del pensamiento inductivo y su convivencia con el método cartesiano se debe acudir al «eclecticismo» con el que Sebold explica en la Poética de Luzán la decantación por los autores modernos frente a los clásicos, la modernidad de algunos pasajes y la apertura a una concepción "orgánica» de la poética. LuzÁn, Ignacio. La Poética. Ed. Russell P. Sebold. Madrid: Cátedra, 2008. Para conocer en mayor profundidad las fluctuaciones del pensamiento ilustrado, es conveniente acudir a CASsirer, Ernst. Filosofía de la Ilustración. México: Fondo de Cultura Económica, 1993 [1932].

32. Revela Olay Valdés la experiencia de Feijoo al leer a Virgilio: "Su majestad heroica me enamora, su grandilocuencia poética me hechiza: aquellos sonoros y soberanos golpes que a trechos deja caer como desde la cumbre del Olimpo sobre la mente del que lee totalmente me arrebatan". Olay VALDÉs, Rodrigo. "La poesía y sus constitutivos esenciales según Feijoo». Cuadernos Dieciochistas, 16, 2015, p. 347.

33. Indica Cebrián que Arjona, como espíritu de la Academia en sus inicios y en su desarrollo, propuso la práctica de elaborar disertaciones orales y certámenes poéticos a partir de su admisión en 1795. Cebrí́n, José. Desde el siglo ilustrado. Sobre periodismo y crítica en el siglo XVIII. Sevilla: Universidad de Sevilla, Instituto Feijoo de Estudios del siglo XVIII, 2003, p. 139. 
en la misma orientación pues alaba al autor del poema épico El Bernardo ${ }^{34}$ (1624) frente a Ariosto. Como crítico y poeta, sobrepone el Orlando a la epopeya sobre Bernardo del Carpio, sin embargo, como crítico y poeta, a la vez que heredero de los discursos en defensa de la nación española, defiende el modelo épico español sobre el italiano ${ }^{35}$. Es más, Lista menciona la clasificación por escuelas de la poesía española, añadiendo que "es bien conocida en la Academia", a través de la cual, Balbuena representa junto a Lope de Vega la escuela "propiamente española». Esta clasificación fue propuesta precisamente por Arjona en su "Plan para una historia filosófica de la poesía española ${ }^{36}$, discurso leído en la misma academia en diciembre de 1798. La elección de nacionalizar la épica, es decir, relevar el mensaje del texto épico por aquello relacionado estrictamente al proyecto nacional, es ofrecer una simplificación de la lectura, es primar el código heroico fundacional frente a otros elementos como la moralidad del poema. Este proceso, característico de la época, revivirá textos anteriormente olvidados, para generar el constructo épico-nacional de finales de siglo. No obstante, ambos documentos difieren entre sí en su formulación comunicativa. Mientras en el de Lista no hay alusiones a la recepción, es decir, se formula en clave de discurso académico, el de Arjona es una respuesta a la interpelación de un amigo literato sobre la opinión que le

34. Para entender el proceso de recuperación del poema épico El Bernardo o Victoria de Roncesvalles (Madrid, 1624) de Bernardo de Balbuena como modelo enfrentado a Ariosto, véase GARCíA-MiNGUILLÁN, Claudia. "La épica de los Jesuitas: juicios y comentarios sobre El Bernardo de Balbuena”. Cuadernos de Estudios del siglo XVIII, 2018, 28, pp. 73-93. Un interesante estudio, a la vez que la edición crítica del discurso de Lista, han sido realizados por Díaz Rosales, Raúl. "Examen del Bernardo de Balbuena. Alberto Lista y Aragón». Analecta Malacitana, 2005, XXVIII, 2, pp. 687-711. Falta todavía por analizar la figura de Bernardo de Balbuena en el entendimiento y la admiración del siglo XVIII, siendo muy relevante la aportación de Durán. DuRÁn LóPEz, Fernando. "Las ediciones de poesía del Siglo de Oro en la prensa de la Ilustración "Seminario de Salamanca" (1793-1798) y "Correo de Sevilla" (1803-1808)». En LARA GARRIDO, José y Molina HuETE, Belén (coords.). Estudios sobre la recepción y el canon de la literatura española. Madrid: Visor, vol. II, 2013, p. 366, quien menciona la «afición de Matute y los sevillanos por Balbuena" en referencia no solo al discurso de Lista, sino además de un trabajo de Justino presentado también ante la Academia de Letras Humanas, titulado Memorias sobre la persona y escritos del obispo de Puerto Rico, el Dr. D. Bernardo de Balbuena, texto recogido por Aguilar PiÑAl, Francisco. "La Academia de Letras Humanas (1793-1801). Manuscritos conservados». Cuadernos Bibliográficos, 1979, n. ${ }^{\circ}$ 38, pp. $159-180$.

35. Como ha señalado Nerlich: «Nicht länger um eine Harmonie zwischen klassizistischen Epenideal und jener primitiven spanischen Epik bemüht, benutzt er das Gedicht vom Mio Cid als Ausgangspunkt zu einem langen Vergleich spanischer und italienischer Epen. [...] Mit Recht, meint Lampillas, könne man vom Mio Cid behaupten, nicht nur, daß er älter sei als Pulcis Morgante, sondern als älteste epische Gedicht Europas in lingua volgare überhaupt. Abgesehen vom Alter gesteht Llampillas dem Mio Cid obendrein auch mehr epische Qualität zu als dem Gedicht Pulcis». NerLich, Michael. Untersuchungen zur Theorie des klassizistischen Epos in Spanien (1700-1850). Genève \& Paris: Droz, 1964, p. 42.

36. Destaca Begoña López Bueno su utilidad «normativa y pragmática» para «adoctrinar a los jóvenes poetas contemporáneos» en LóPEz BuENo, Begoña. "Las escuelas poéticas españolas en los albores de la historiografía literaria: Arjona y Reinoso". Philologia Hispalensis, 1989, 4, pp. 305-317. 
inspiran las ideas literarias de Juan Andrés. Expresiones como «mi amigo y señor», "quiere vd. que le diga", "tal vez parecerá a vd. mismo", etcétera, sugieren un acto comunicativo más privado. Con toda probabilidad se trata de una respuesta en medio de uno de los debates que con certeza sucederían en el trascurso de las actividades de la Academia, recogidas en las actas ${ }^{37}$, entre las figuras representativas de la institución.

\section{El Debate sobre la teoría: las ideas de Boileau y Muratori en JuAn Andrés}

La disertación de Manuel María de Arjona encuentra su base en temas siempre presentes en la teoría de la épica. La acción del poema, la caracterización del héroe y la fábula son aspectos que sustentan su reflexión crítica para mostrar su preferencia por el autor moderno. La dialéctica de la comparación no solo se observa entre los autores antiguos y modernos, sino en autores cercanos a Homero y Virgilio, cuyos poemas fueron habitualmente comparados en detrimento de La Aquileida de Estacio o Las Argonáuticas de Apolonio. Este método sirvió también para comparar los poemas contemporáneos como Las aventuras de Telémaco (1699) de Fénelon o La Henriada (1723) de Voltaire, y, a pesar de que las obras cambien, los elementos señalados y debatidos suelen ser los mismos; así se observa en la disertación de Arjona. Lo habitual de estos rasgos se debe a que no inicia su reflexión ab ovo, sino a partir de la lectura de Juan Andrés, quien es, a su vez, conocedor de la tradición crítica de Boileau y Muratori. Como nombres representativos de la preceptiva de entre siglos, en sus obras, respectivamente, L'Art poéti$q u e^{38}$ (1674) y Della perfetta poesia italiana (1706), se establece un diálogo sobre los principios teóricos del género. De esta manera, Boileau declara su parecer estrictamente ligado a la estética clásica, frente a Muratori, quien en una estética más flexible observa un espacio para reivindicar los autores italianos en un factor emocional de nacionalismo literario. Boileau, como representante del clasicismo y principal voz contra los poetas modernos, trató a Homero en una sucesión de alabanzas. La denuncia de Muratori, sin embargo, se dirigió hacia la poca mención a los autores italianos por parte de los teóricos. También en la de la consideración del francés, quien anima a los futuros poetas a evitar el estilo italiano: "Evitons ces excès: laissons à l'Italie / de tous ces faux brillants l'éclatante folie „39. No hay duda

37. Hemos consultado las actas de la Academia de Letras Humanas de Sevilla del periodo 1793-1797, con la signatura A 333/209, del fondo antiguo de la Universidad de Sevilla. http://fondosdigitales.us.es/fondos/libros/1724/157/actas-de-la-academia-de-letras-humanas-de-sevilla-1793-1797/ vista_amplia/, fecha de consulta: 27/02/2019.

38. Remito a la edición crítica del arte poética de BoIlEAu-Despréaux, Nicolas. L'art poétique. Ed. Sylvain Menant. Paris: Garnier-Flammarion, 1998.

39. Boileau-Despréaux, Nicolas. L'art poétique. Ed. Sylvain Menant. Paris: Garnier-Flammarion, 1998, canto I, vv. 45-46. 
de que por «estruendosa locura» Boileau piensa en el Orlando y la máquina de su fábula compuesta por disparates y juegos de la fantasía, esquema muy alejado del ideal de equilibrio y mesura clásico ${ }^{40}$. Muratori, en respuesta al crítico, habla de "la poesia nostra» que "dal Petrarca al Tasso, si valse di questi "lodevoli deliri" della fantasia che [...] si mostrano incapaci di intendere ${ }^{41}$. La postura del italiano se sitúa menos extrema en el marco de la querella. Reconoce el valor y el defecto de los cantos homéricos. Como crítico, también participa de la valoración del resto de poemas épicos menos defendidos como la Aquileida de Estacio y se permite una elegante burla parodiando el "tout ce qu'il [Homère] a touché se convertit en or" ${ }^{42}$ de Boileau. Como indican Falco y Forti ${ }^{43}$, la obra de Muratori sobre la poesía italiana, cuyo título es ya de por sí reivindicativo, queda cimentada en el rechazo al concepto de "autoridad" que engloba la aceptación de la imposibilidad de igualar a los autores clásicos y de innovar en la composición lírica.

El punto de partida y motivación de la carta, la obra de Juan Andrés, Origen, progresos y estado actual de toda la literatura (1784-1806), se localiza en un espacio de teoría y erudición. Las observaciones del erudito jesuita se sostienen en una discusión sobre el género épico que alberga rasgos de tradicionalidad en el debate literario. Juan Andrés, posicionándose a favor de la épica quinientista italiana, posicionándose, por tanto, a favor de lo denunciado por Muratori -la denuncia por la ausencia de autores italianos, además de la discusión sobre ideas teóricas-, plantea y discute la equiparabilidad de los antiguos y los modernos en los perfiles de Virgilio y Tasso. Formula, haciendo despliegue de su característica erudición, su conocimiento del debate épico sucedido durante la primera mitad del siglo. En sintonía con Voltaire, Juan Andrés reconoce en Camoens, Tasso y Ariosto -mas no en Milton- una épica que recupera el nivel de los cantos épicos grecolatinos. Reconoce, como cualquier lector, la sublimidad de los clásicos y su superioridad por ser antiguos y genuinos en su género. Este reconocimiento mantenido casi como un rezo compulsivo por la escuela de Boileau es confrontado por la reflexión en el estilo del autor clásico. Juan Andrés confiesa su predilección por Tasso, precisamente por su cercanía en el lenguaje. René Le Bossu (1631-1680), autor del Traité du poème épique (1675), identifica como rasgo esencial de los autores antiguos la complejidad y oscuridad de la expresión, rasgo en contraste con la preferencia de

40. La falta de correspondencia de la épica italiana con el rigor clásico no afectó, empero, a su éxito.

41. Muratori, Lodovico Antonio. Opere di Lodovico Antonio Muratori. A cura di Giorgio Falco e Fiorenzo Forti. Milano-Napoli: Riccardo Ricciardi Editore, 1964, p. 59

42. Bolleau-DespréAuX, Nicolas. L'art poétique. Ed. Sylvain Menant. Paris: Garnier-Flammarion, 1998, canto III, vv. 298. (Ov. Metamorf. XI.v. 1029).

43. Muratori, Lodovico Antonio. Opere di Lodovico Antonio Muratori. A cura di Giorgio Falco e Fiorenzo Forti. Milano-Napoli: Riccardo Ricciardi Editore, 1964, p. 59. 
Juan Andrés en Tasso por sus «descripciones risueñas y brillantes y en todo lo que es amenidad y gentileza " ${ }^{44}$.

\section{Homero de Roma vs. Homero de Ferrara}

La auctoritas de los clásicos, atribuida por los preceptistas, recubría también la palabra de los teóricos partidarios. Con el cambio del pensamiento surgieron voces que discutían y, a la vez, contradecían a los teóricos. Los más conocidos fueron contestados duramente por Voltaire en su Essai sur la poésie épique (1728). En él llamaba a los preceptistas «tyrans, prétendus législateurs» para concluir que, entre los teóricos, son Boileau y Le Bossu los que se comportan como «les astronomes qui inventaient tous les jours des cercles imaginaires».

Partiendo de este principio de duda de la preceptiva, se produce un giro hacia las voces de crítica literaria y, en el caso del Correo de Sevilla, se genera un intercambio de ideas entre literatos. El autor supone que su interlocutor, el solicitante de su opinión y reflexión, conoce «lo mucho que sobre este asunto se ha escrito en Italia y Francia». Y añade que, aun no conociéndola, lo que interesa a su interlocutor es saber "lo que yo pienso, no lo que han pensado los demás». Esta cesión de protagonismo es un testimonio que cuestiona lo anteriormente dicho y supone un nuevo parecer en el método de la crítica. En este momento, el gran crítico y el lector cuestionan con la misma voz de autoridad los clásicos literarios.

El "Homero de Ferrara», como se conocerá a Tasso en algunos diarios de época, irrumpe con un elemento estructural del debate en torno a la épica que no alberga discusión alguna, el de la religión del poema. La dicotomía entre la creencia de autores paganos frente a los del verdadero dogma compone una de las ramas de la dialéctica literaria del género. Paul Rolli, crítico italiano afincado en Inglaterra, defensor de la corriente clásica y enemigo acérrimo del pensamiento de Voltaire, publica la réplica Remarks upon M. Voltaire's Essay on the epick poetry of the European nations ${ }^{45}$ (1728). Entre los muchos errores y defectos que señala en el filósofo francés, destaca la convicción de un profundo cambio social ocurrido en el transcurso de los siglos, especialmente, con los últimos cambios en la maquinaria bélica. Voltaire viene a decir que la invención de la pólvora, la brújula y la imprenta han modificado radicalmente la manera de ver el mundo y esto ha afectado a la composición de la épica. Rolli añade que el único combate que atrae

44. ANDRÉs, Juan. Origen, progresos y estado actual de toda la literatura, tomo III. Madrid: Sancha, 1785 , pp. 280-281.

45. Citamos el texto francés, aprobado por el mismo autor, que se publicó en París poco después de la edición original: Rolli, Paul. Examen de l'Essai de M. de Voltaire sur la poesie epique. Paris: Rollin Fils, 1728. Este ataque a Voltaire convive con el panfleto La Voltairomanie, ou Lettre d'un jeune avocat en forme de mémoire: en réponse au libelle du sieur de Voltaire intitulé "le Préservatif». Paris, 1738 . 
la atención del poeta es el enfrentamiento físico entre héroes y añade, además, cuál ha sido el verdadero cambio:

Le plus grand changement qui se soit fait a eté sans contredit ce qui concerne la religion, mais après tout en quoi a consisté ce changement? Dans la difference des objets \& des rits. Les temples, les autels, les prêtres, n'ont pas pour cela changé de nom: les termes d'adoration, de prieres \&c. sont demeurés en possession de signifier ce qu'ils signifioient auparavant. Toutes les passions humaines, tous les objets de la nature qui servent de fonds aux descriptions, aux comparaisons des poetes, subsistent, je ne dis pas depuis Homere, mais depuis Adam $[\ldots]^{46}$.

No es casualidad que la comparación entre Virgilio y Tasso ${ }^{47}$ de Arjona comience precisamente con el elemento religioso que otorga indiscutiblemente la preferencia al de Ferrara. La acción de un poema que narra la conquista de una ciudad originalmente propia del padre de la religión del autor, frente a la de dioses paganos -adviértase la contraposición entre Roma y Jerusalén-, nunca será inferior a ningún poema de la antigüedad. La reflexión profundiza en estos escollos y es el personaje el que fomentará la decisión. Godofredo aporta en detrimento de Eneas un vigor más propio de un miles y de un político, frente al héroe latino cuyas virtudes se concentran en la piedad y en su naturaleza compartida con la divinidad: "Godofredo me tendría siempre en suspenso, amando y respetando sus virtudes», frente a Eneas que, a su lado, "se había de fastidiar cualquiera muy pronto".

Arjona, en su faceta de crítico literario, considera que la acción y la caracterización del héroe son elementos que motivan la elección de un poema frente al otro. La auctoritas que envolvía la figura del autor antiguo se desprende ya como el velo en el pedestal marmóreo de Camillo Torreggiani de Isabel II velada. Frente a dichas preferencias, más acorde a una primera lectura emocional ${ }^{48}$, el análisis se reanuda en un hilo de discusión sobre el estilo de los autores. El «tejido», como lo denomina, se mantiene superior en la obra antigua frente a la moderna. Aunque Tasso, diga el autor, consiga formar algunos elementos de una manera superior a Virgilio, el estilo de este sí alcanza lo sublime. El gusto por lo sublime se sitúa en la misma corriente clasicista a partir de la traducción que Boileau realizó del

46. RoluI, Paul. Examen de l'Essai de M. de Voltaire sur la poesie epique. Paris: Rollin Fils, 1728, pp. 7-8.

47. Luis Alberto de Cuenca, en su artículo publicado en $A B C$ el 10 de junio de 1998, titulado "Virgilio y yo", mantiene la pervivencia de este tipo de comparaciones entre los autores de épica: "Quiero decir, en fin, que Tasso es como Virgilio y Ariosto como Homero, y que Tasso y Virgilio son más densos y "doctrinales" que Ariosto y Homero, aunque no menos disparatados". Disponible en línea, fecha de consulta 20/05/2019: https://www.abc.es/archivo/periodicos/abc-madrid-19980610-3.html.

48. Una lectura emocional debe partir del principio de verosimilitud. Para entender cómo condicionó en el proceso de constitución de los géneros literarios a lo largo de la Ilustración es conveniente consultar RODRíGuEz SÁNCHEZ DE LEÓN, María José. "Verosimilitud literaria y experiencia estética en la Ilustración». eHumanista, 2014, 27, pp. 52-62. 
tratado de Longino ${ }^{49}$, publicado el mismo año que su Arte Poética. Esto fundamenta -y expande- el eclecticismo natural en una época de profundos cambios. La naturaleza del estilo de cada autor fomenta de igual modo una especificidad en la lectura y promueve un clásico para distintos momentos del ánimo. Como deja indicado el autor: "Virgilio es más sublime y el Tasso más ameno".

En este sentido, el autor parece decantarse por Virgilio en su querella argumentada dado que en lo que se refiere a la formación del infierno ${ }^{50}$ de Tasso, dice, pervive un aire "monacal" cuyo estilo considera más apto para una pintura sobre la muerte y el juicio final. Además, afirma que los episodios de la Eneida se presentan plagados de la máquina divina pagana, lo que no afecta al mérito de la obra ni contraviene a "los inteligentes». En este aspecto pierde posición con respecto a Muratori, quien afirma todo lo contrario, esta vez, de la Iliada:

La maniera con cui i Greci si renderono padroni di Troia [Virgilio, Eneida], la virtuosa gara di Leone e Ruggiero [Ariosto, Orlando], la morte di Clorinda [Tasso, Gerusalemme] e altri simili fatti senza macchine soprumane sono maravigliosi e hanno quel nobile verisimile che da noi si desidera. Per lo contrario non sappiamo intendere come gli antichi potessero commendar cotanto Omero, che nulla fa quasi operare agli eroi senza gli dei in macchina. [...] Il furore del fiume Xanto, Vulcano che abbrucia il fiume e cento altre somiglianti operazioni rapportare nell'Iliade, non dovrebono ora lodarsi, perché non verisimili alla natura di quelle cose, considerata dagli uomini saggi ${ }^{51}$.

Sin embargo, la pintura de Virgilio de los campos Elíseos roza el patetismo y la pomposidad y se aleja de la "virtud heroica", rasgo necesario para el espacio en el que se corona a los héroes. Con todo, el autor mantiene su argumentación en su elección por Tasso alegando: "Pero esto no quiere decir que Virgilio no deba ser inferior al Tasso». La pérdida de la auctoritas anteriormente mencionada es favorecida por la preferencia del autor, que es lector y, por tanto, defensor de la épica de la Gerusalemme. Como resultado, el argumento final, y definitivo, para sostener el debate será la presencia de elementos que favorezcan la experiencia estética de la lectura. Se realiza, a continuación, un análisis de gran belleza, y no menos interés, del proceso psicológico de la lectura de un poema épico frente a la del otro para finalizar con el gusto por lo caballeresco y la "terneza de afectos" ${ }^{52}$.

49. Boileau-Despreaux, Nicolas. Oeuvres diverses du sieur D*** avec le Traité du sublime ou du merveilleux dans le discours. Paris: Denys Thierry, 1674.

50. John Dennis (1658-1734), crítico y dramaturgo inglés, también comparará la descripción del infierno de Milton con el de Virgilio en sus Critical Works, aspecto que establece los loci communis de la teoría de la épica.

51. Muratori, Lodovico Antonio. Opere di Lodovico Antonio Muratori. A cura di Giorgio Falco e Fiorenzo Forti. Milano-Napoli: Riccardo Ricciardi Editore, 1964, p. 82.

52. Correo de Sevilla, del miércoles 15 de octubre de 1806, n. $^{\circ} 318$, p. 36. 


\section{LA TERNEZA DE AFECTOS: EXPERIENCIA ESTÉTICA DEL CRÍTICO-LECTOR}

Resulta, por tanto, sorprendente que un paralelo entre dos autores desvele principios diferentes de valoración. El mismo lector valora a Virgilio por lo heroico de su fábula, por el "tejido» sublime, generador de un placer más bien técnico y distanciado. Todo lo contrario parece advertir en el Tasso, por cuyos personajes siente una atracción y admiración que roza lo puramente emocional. Esta aparente contradicción, que parece valorar los poemas con dos criterios enfrentados, corresponde a la interpretación del texto habitual en su época. Munárriz, en su traducción a la obra de Hugo Blair, Lecciones sobre la retórica y las bellas letras (1798-1801), formula esta dicotomía:

Algunas veces puede el poeta ser grave y majestuoso, pero ha de ser también otras tierno y patético y ha de presentarnos escenas delicadas y placenteras del amor, la amistad y el cariño. Bajo este respeto no conozco poetas épicos más felices que Virgilio y Tasso ${ }^{53}$.

De ahí se justifica la doble tendencia del crítico ${ }^{54}$. Su atención se concentra en la explicación de su lectura emocional a partir del héroe de Virgilio, es decir, su experiencia estética confrontada a la lectura de Tasso, la cual se rige por la experiencia sensible. Esta doble vivencia del género épico se explica a partir de la taxonomía de la experiencia estética de Jauss ${ }^{55}$ en la que diferencia, entre otras fases, la identificación "admirativa» con el héroe frente a la identificación «simpatética». Esta convivencia se aprecia en las reglas que formula el padre Juan Andrés para la composición del poema épico:

Elegir un argumento digno del canto de las Musas, a quienes invoca el poeta, preparar y ordenar toda la fábula de tal manera, que no discorde el medio del principio, ni el fin del medio y que resplandezca la verosimilitud en toda la historia y en cualquier hecho particular, tanto que sea verdadero como falso, encontrar oportunos episodios que sirvan al poema de natural y propio ornamento, y no de lustre afectado y postizo, que lejos de estar desunidos del resto de la fábula tengan necesaria conexión y real dependencia de ella misma estudiar los caracteres de las personas, pintarlos al natural y hacerlos visibles en las acciones y en los discursos, siguiendo en todo escrupulosamente cuanto nos presenta la naturaleza bien observada, colorir graciosamente las descripciones, animar las narraciones, buscar escenas afectuosas y patéticas, [la cursiva es nuestra] procurar que haya variedad y naturalidad en los

53. Citamos a Blair y Munarriz a partir de la edición completa de la obra: BlAIR, Hugh. Compendio de las lecciones sobre la retórica y bellas letras. Trad. José Luis Munarriz. Madrid: Ibarra, 1815, p. 367.

54. Se confirma por tanto la separación entre razón y sentimiento que tanto alterará el modelo del pensamiento ilustrado, como aborda la obra de CASsIRER, Ernst. La Filosofía de la Ilustración. México: Fondo de Cultura Económica, 1993, y SÁNCHEZ-Blanco, Francisco. Europa y el pensamiento español del siglo XVIII. Madrid: Alianza, 1991.

55. Jauss, Hans Robert. Experiencia estética y bermenéutica literaria. Ensayos en el campo de la experiencia estética. Madrid: Taurus, 1992, p. 264. 
hechos y decoro y majestad en el estilo y en suma poner por obra cuanto una fogosa fantasía, un fecundo ingenio, un severo juicio, una vasta doctrina y una viva elocuencia puedan sugerir al docto poeta, es lo que se requiere para una perfecta epopeya. Y así ¿quién podrá justamente maravillarse de que en tantos siglos como ha que los hombres cultivan la poesía, aun no se haya formado un poema épico que pueda llamarse perfecta y de que habiéndose compuesto tantos poco acreedores a la luz pública, sean tan pocos los que han conseguido el aprecio de los posteriores, y se hacen leer con gusto? ${ }^{56}$.

Este «buscar escenas afectuosas y patéticas» como rasgo compositivo de la epopeya es una muestra más de lo que busca el lector cuando lee una obra perteneciente al género épico. La demanda de lirismo hace frente a las normas establecidas desde la teoría aristotélica, para apostar por la expresión extremada del sujeto en el espacio literario y reforzar, así, la experiencia estética como centro de la lectura. Batteux, en la traducción de Arrieta a Principios filosóficos de la literatura o curso razonado de Bellas Letras y de Bellas Artes (1797-1801), ya identifica ambas tendencias de admiración racional y admiración sensible en la épica:

El tono de oráculo nos conmueve y la verosimilitud de las cosas nos convence. Oímos una voz sublime, sentimos un fuego divino que nos abrasa, reconocemos las ideas que tenemos de la conducta de la deidad con respecto a los hombres, vemos además héroes, acciones y costumbres pintadas con rasgos que conocemos, olvidamos la ficción y la abrazamos como a la verdad, amamos todos estos objetos, si no existen, merecen existir, y la naturaleza ganaría en ello, si fuese tan bella como el arte. Así creemos sin violencia que es la misma naturaleza, ¿y no podremos decir que es ella supuesto que la creemos? ?7 $^{57}$

La admiración que despiertan Homero y Virgilio se ha transmitido a través de la metáfora del calor y del fuego. Blackmore en el prefacio a su poema histórico-épico King Arthur (1697) añade: "Homer has more of the poetical inspiraton. His fire burns with extraordinary heat and vehemence, and often breaks out in flashes, which surprise, dazle and astonish the reader ${ }^{58}$. John Dryden señala en Fables ancient and modern (1700) "You never cool while you read Homer" "59. Más tarde, Pope, en su traducción a La Ilíada publicada en 1713, sostiene: "It is to the stregth of this amazing invention we are to attribute that unequalled fire and rapture, which is so forcible in Homer, that no man of a true poetical spirit is master

56. ANDRÉs, Juan. Origen, progresos y estado actual de toda la Literatura obra escrita en italiano por el abata D. Juan Andrés y traducido al castellano por D. Carlos Andres. Madrid: Sancha, 1784, tomo III, pp. 190-191.

57. Batteux, Charles. Principios filosóficos de la literatura o curso razonado de Bellas Letras y de Bellas Artes. Trad. Agustín García de Arrieta. Madrid: Sancha, 1797, p. 184.

58. Blackmore, Richard. King Arthur. An Heroick poem in twelve books. London: Awnsham et al., 1697, p. XV.

59. DRYDEN, John. "Preface». En Fables ancient and modern; translated into verse, from Homer, Ovid, Boccace, E Chaucer: with original poems. London: Jacob Tonson, 1700. 
of himself while he reads him ${ }^{60}$. Esta violencia del ánimo, reforzada por el origen de la epopeya en la imitación a la naturaleza, sostiene y aclara en la tradición de la crítica a lo largo del siglo la conclusión del autor de la carta con respecto a la Eneida. De su lectura relata la experiencia de la identificación admirativa al confesar: "Cuando siento el espíritu más vigoroso hecho al punto mano de Virgilio y me parezco a mí mismo ya penetrado del espíritu sublime de sus héroes», de tal manera que se confirma la sensación que transmiten los clásicos en un poetical spirit. Sin duda, uno de los enlaces de unión es el personaje heroico. Su admiración no se fundamenta en el efecto trágico o en la experiencia cómica. Jauss indica que ese placer viene producido por el distanciamiento ${ }^{61}$ - -acto distanciador»- que fomenta la idealización del héroe y, por tanto, la experiencia estética proviene de un efecto de búsqueda de un modelo de imitación involuntaria. Hegel recurrió al elemento de la distancia como uno de los rasgos de la epopeya original. Criticaba al poeta que intervenía en el texto de su epopeya sin recurrir a los personajes o a la máquina divina, norma platónica de la que deja constancia en su Estética: «El poeta debe como sujeto retroceder frente a su objeto y desaparecer en este [...] el gran estilo épico consiste en que la obra parezca cantarse para sí y se presente autónoma, sin tener a un autor en la cabecera " ${ }^{62}$. La distancia favorece, sin embargo, el surgimiento del héroe interior que la lectura del poema épico hace surgir en cada lector. El espacio emocional con el desarrollo de un heroísmo ya no épico, sino lírico, promueve y genera el reconocimiento de uno mismo ${ }^{63}$. La teoría del reconocimiento, de la anagnórisis, abarca en Ricoeur varios niveles. Es la división de la lectura reflexiva no solo de reflexión, sino de "ipseidad" "64, que favorece la referencia a uno mismo a través de la virtud del héroe. Este reconocimiento se produce con el "qué» y el "cómo", para alcanzar la "autodesignación». El qué es la lectura épica, el testimonio de la vida de un héroe, posteriormente, alcanza el reconocimiento en el modo, una lectura emocional y empática ${ }^{65}$.

60. Pope, Alexander. The Iliad of Homer. London: Charles Rivington, 1760, p. V.

61. JAuss, Hans Robert. Experiencia estética y hermenéutica literaria. Ensayos en el campo de la experiencia estética. Madrid: Taurus, 1992, pp. 264.

62. Hegel, Georg Wilhelm Friedrich. Lecciones sobre la estética. Trad. A. Brotóns Muñoz. Torrejón de Ardoz: Akal, 1989.

63. Resultan reveladoras las siguientes palabras de Lukács: «En el mundo de las distancias, todo verso épico se transforma en poesía lírica (aunque escritos en verso, Don Juan y Onegin pertenecen al conjunto de las grandes novelas humorísticas) pues en el verso, todo lo oculto se vuelve manifiesto, y en su vuelo ligero, desnuda, burla, ignora la distancia que pacíficamente recorre la prosa en su camino por alcanzar el sentido, o meramente la considera un sueño dejado en el olvido». LukÁcs, Georg. Teoría de la novela. Un ensayo bistórico-filosófico sobre las formas de la gran literatura épica. Buenos Aires: Ediciones Godot, 2010, p. 53.

64. Ricoeur, Paul. Caminos del reconocimiento. Trad. Agustín Neira. México D.F.: Fondo de Cultura Económica, 2006, pp. 120-125.

65. Acaso puede ser este uno de los inicios estéticos de las "vivencias poéticas reales» que ha señalado Cassirer en la escuela estética suiza con la búsqueda de la fenomenología del genio poético. CAssirer, Ernst. La Filosofía de la Ilustración. México: Fondo de Cultura Económica, 2000, p. 368. 
Con todo, este efecto distanciador como indicio de la experiencia estética admirativa no se mantiene puramente aislado de la simpatética pues, como indica Jauss $^{66}$, existe una relación de consecuencia entre ambos tipos de identificación. Estos tipos de experiencia no excluyentes entre sí explican por qué, entre todos los elementos del tradicional debate sobre el género épico, el autor de la carta se decanta por explicar su experiencia lectora y su preferencia por los personajes femeninos.

\section{HACIA LA DERIVA DE LA ÉPICA: APUNTES FINALES}

Jauss afirma que la alternancia entre los géneros llevó a la epopeya hacia su decadencia. Esta afirmación no es discutible, efectivamente, la epopeya sí sucumbió a la irrupción de otros géneros literarios. No obstante, se debe matizar el fin de la epopeya como una desaparición esporádica. Todo lo contrario, puesto que, como hemos ido analizando a lo largo del trabajo, el género épico intentó adaptarse al nuevo gusto en muchos aspectos y matices. La epopeya desapareció en su manifestación más fiel a su versión clásica, pero este epos originario -en la terminología hegeliana- no engloba esa 'épica intermedia' producida especialmente a lo largo del siglo XVIII. Arrieta, en el Batteux español, confirma de manera muy esclarecedora la unión de los tres estilos:

Mientras la acción continua en el drama o en la epopeya la poesía es épica o dramática cuando se detiene y solo pinta la situación del alma y el puro sentimiento que esta experimenta, entonces es de suyo lírica y no se necesita más que la forma conveniente para ponerla en canto $^{67}$.

Batteux inaugura la presencia dramática en los discursos internos al poema épico. Este elemento no solo coincide con la conexión emocional que Arjona manifiesta por los personajes femeninos, sino que explica los cambios producidos por los autores de épica durante el siglo ilustrado. En una primera instancia, advertimos

Pozuelo Yvancos, al analizar el canon y la teoría de Harold Bloom señala el criterio de "fuerza estética». Pozuelo Yvancos, José María. "Teoría del Canon». En Pozuelo Yvancos, José María y Aradra SÁnchez, Rosa María. Teoría del canon y literatura española. Madrid: Cátedra, 2000, p. 35.

66. Jauss, Hans Robert. Experiencia estética y bermenéutica literaria. Ensayos en el campo de la experiencia estética. Madrid: Taurus, 1992, p. 270. Lotman lo expresa en la síntesis entre lo práctico y lo convencional, sobre el verso de Pushkin Me desharé en lágrimas ante la ficción, añade: "Se trata de una brillante caracterización de la doble naturaleza del comportamiento artístico. Aparentemente, la conciencia de que nos hallamos ante una ficción debería excluir las lágrimas. O por el contrario: el sentimiento que suscita las lágrimas nos haría olvidar que nos encontramos ante una ficción. De hecho, ambos tipos -opuestos- de conducta existen de modo simultáneo ahondándose mutuamente». LOTMAN, Yuri M. Estructura del texto artístico. Madrid: Istmo, 1970, p. 89.

67. Batteux, Charles. Principios filosóficos de la literatura o curso razonado de Bellas Letras y de Bellas Artes. Trad. Agustín García de Arrieta. Madrid: Sancha, 1797, p. 226. 
una concentración lectora, motivada por esa lectura emocional, en el personaje. Aún sin elementos que lo puedan confirmar, es lógico identificar el surgimiento del elemento nacional como principal rasgo de pervivencia de lo épico. La recuperación de los mitos fundacionales, en sustitución a la epopeya y su expansión al resto de géneros -tragedias sobre Pelayo o el Cid-, es motivada por este tipo de lectura. En resumen, la lectura admirativa nos dirige a la epopeya clásica, mientras que la lectura simpatética permite al lector situarse en el lugar de su personaje, entrar en comunión emocional con él, desde la distancia necesaria para la experiencia, desde el «mecanismo de evasión». Esta sensibilización del héroe se aprecia en los poemas épicos compuestos a lo largo del siglo. Precisamente, Voltaire fue criticado por la caracterización de su héroe Enrique IV en su poema épico La Henríada. En él, el personaje heroico expresaba líricamente su sufrimiento por el enfrentamiento civil al que Francia parecía estar abocada. Sin embargo, la trama se resuelve a través de acciones no bélicas, dejando a un lado los rasgos elementales de una epopeya y permitiendo a las emociones sobresalir como conducto de resolución pacífica de un conflicto. En definitiva, lo que ampara el cambio -y decadencia- del género épico es el mayor espacio requerido por el sujeto para argumentar todas esas emociones que adquieren protagonismo incluso en el género, según Bajtín, más cristalizado y fosilizado.

Con estos breves apuntes, que distan de ser concluyentes, se deben revisar las afirmaciones que narran el origen de la novela, tanto en lo que ofrece más allá del género épico y en ausencia de este. Observar la génesis del fin de la épica en sus fases fronterizas con el siglo y los géneros literarios dará nueva luz a la comprensión de la estética de la novela.

\section{Bibliografía}

Actas de la Academia de Letras Humanas de Sevilla del periodo 1793-1797, manuscrito A $333 / 209$, del fondo antiguo de la Universidad de Sevilla.

Aguilar PiÑal, Francisco. «La Academia de Letras Humanas (1793-1801). Manuscritos conservados". Cuadernos Bibliográficos, 1979, n. ${ }^{\circ} 38$, pp. 159-180.

Aguilar Piñal, Francisco. La Real Academia Sevillana de Buenas Letras en el siglo XVIII. Sevilla: Colegio Oficial de Aparejadores y Arquitectos técnicos de Sevilla, 2001, p. 26.

ÁlvareZ BARrientos, Joaquín. La novela del siglo XVIII. Madrid: ediciones Júcar, 1991.

ÁLVAREZ BARRIENTOS, Joaquín (ed.). Se hicieron literatos para ser políticos. Cultura y política en la España de Carlos IV y Fernando VII. Madrid: Biblioteca Nueva - Servicio de Publicaciones de la Universidad de Cádiz, 2004, pp. 25-62.

Álvarez BARrientos, Joaquín; López, François y URZAINQUi, Inmaculada. La República de las Letras en la España del siglo XVIII. Madrid: Consejo Superior de Investigaciones Científicas, 1995, p. 177.

ANDRÉs, Juan. Origen, progresos y estado actual de toda la Literatura obra escrita en italiano por el abata D. Juan Andrés y traducido al castellano por D. Carlos Andres. Madrid: Sancha, tomo III, 1784. 
LOS REFERENTES TEÓRICOS, LITERARIOS Y ESTÉTICOS DE LA ÉPICA DIECIOCHESCA...

ARADRa SÁNCheZ, Rosa María. "El canon en la literatura española (siglos XVIII y XIX)». En Pozuelo Yvancos, José María y Aradra SÁnchez, Rosa María. Teoría del canon y literatura española. Madrid: Cátedra, 2000, pp. 143-303.

Bajtin, Mihail. Teoría y estética de la novela. Madrid: Taurus, 1989.

Batteux, Charles. Principios filosóficos de la literatura o curso razonado de Bellas Letras y de Bellas Artes. Trad. Agustín García de Arrieta. Madrid: Sancha, 1797, p. 22.

Biblioteca de autores españoles. Poetas líricos del siglo XVIII, tomo II. Madrid: Rivadeneyra, 1871, pp. 499-504.

Blackmore, Richard. King Arthur. An Heroick poem in twelve books. London: Awnsham et al., 1697.

BLAIR, Hugh. Compendio de las lecciones sobre la retórica y bellas letras. Trad. José Luis Munarriz. Madrid: Ibarra, 1815.

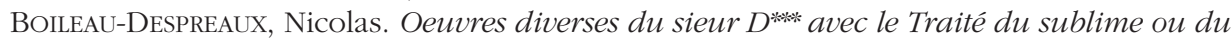
merveilleux dans le discours. Paris: Denys Thierry, 1674.

Bolleau-Despréaux, Nicolas. L'art poétique. Ed. Sylvain Menant. Paris: Garnier-Flammarion, 1998.

Bossu. Traité du poeme epique. Paris: Michel Le Petit, 1675.

CADAlso, José. Cartas marruecas. Ed. Jesús Cañas Murillo Madrid: Academia del Hispanismo, 2016

CASsirer, Ernst. Filosofía de la Ilustración. México: Fondo de Cultura Económica, 1993.

CASTAÑÓN, Jesús. La crítica literaria en la prensa española del siglo XVIII (1700-1750). Madrid: Taurus, 1973.

CEBRIÁn, José. Desde el siglo ilustrado. Sobre periodismo y crítica en el siglo XVIII. Sevilla: Universidad de Sevilla - Instituto Feijoo de Estudios del siglo XVIII, 2003.

CHECA BeLtrÁn, José. «Sobre la virtualidad estética de la materia cristiana: Quintana y Blanco White». En Hernández Guerrero, José Antonio et al. (eds.). Retórica, Literatura y Periodismo. Actas del V Seminario Emilio Castelar. Cádiz: Universidad de Cádiz, 2006, pp. 113-122.

Correo de Sevilla, del sábado 4 de octubre de 1806, n. ${ }^{\circ} 315$, pp. 9-12.

Correo de Sevilla, del miércoles 15 de octubre de 1806, n. ${ }^{\circ} 318$, pp. 33-36.

Danielson, Dennis (ed.). The Cambridge Companion to Milton. Cambridge: Cambridge University Press, 1999.

Díaz Rosales, Raúl. «Examen del Bernardo de Balbuena. Alberto Lista y Aragón». Analecta Malacitana, 2005, XXVIII, 2, pp. 687-711.

DRYDEN, John. "Preface». En Fables ancient and modern; translated into verse, from Homer, Ovid, Boccace, \& Chaucer: with original poems. London: Jacob Tonson, 1700.

DuRÁn LóPEZ, Fernando. "Las ediciones de poesía del Siglo de Oro en la prensa de la Ilustración "Seminario de Salamanca" (1793-1798) y "Correo de Sevilla" (1803-1808)». En Lara Garrido, José y Molina Huete, Belén (coords.). Estudios sobre la recepción y el canon de la literatura española. Madrid: Visor, vol. II, 2013, pp. 347-478.

Enciso ReCio, Luis M. «Prensa y opinión pública». En Historia de España por Ramón Menéndez Pidal, tomo XXIX. Madrid: Espasa Calpe, 1985, pp. 195-258.

García-Minguillán, Claudia. "La épica de los Jesuitas: juicios y comentarios sobre El Bernardo de Balbuena.. Cuadernos de Estudios del siglo XVIII, 2018, 28, pp. 73-93.

GRIFFIN, Dustin. "Milton and the Decline of Epic in the Eighteenth Century». New Literary History, 1982, vol. 14, n. ${ }^{\circ}$, pp. 143-154. 
Hegel, Georg Wilhelm Friedrich. Lecciones sobre la estética. Trad. A. Brotóns Muñoz. Torrejón de Ardoz: Akal, 1989.

JAuss, Hans Robert. Experiencia estética y hermenéutica literaria. Ensayos en el campo de la experiencia estética. Madrid: Taurus, 1992.

JOHnson, Samuel. «The Lives of the Most Eminent English Poets». En The Works of Samuel Johnson. London, vol. II, 1787, pp. 82-176.

LADVOCAT, Jean Baptiste. Diccionario histórico abreviado. Madrid: imprenta de Joseph Rico, tomo IV, 1754, pp. 289-292.

LARA GaRRIDO, José. Los mejores plectros. Teoría y práctica de la épica culta en el Siglo de Oro. Málaga: Universidad de Málaga, 1999.

LECOQ, Anne-Marie. La Querelle des Anciens et des Modernes: XVIIe-XVIIIe siècles. Paris: Gallimard, 2001.

LE GENTIL, Georges. Les revues littéraires de l'Espagne pendant la première moitié du XIXe siècle. Aperçu bibliographique. Paris: Hachette, 1909.

LOTMAn, Yuri M. Estructura del texto artístico. Madrid: Istmo, 1970.

LukÁcs, Georg. Teoría de la novela. Un ensayo histórico-filosófico sobre las formas de la gran literatura épica. Buenos Aires: Ediciones Godot, 2010.

Luque Moreno, Jesús. Horacio Lírico. Granada: Universidad de Granada, 2012.

LuZÁn, Ignacio de. La Poética. Ed. R. P. Sebold. Madrid: Cátedra, 2008.

MarnI, Archimede. Allegory in the French Heroic Poem of the Seventeenth Century. Princeton: Princeton University Press, 1936.

Menéndez Pelayo, Marcelino. Historia de las ideas estéticas en España, III. Madrid: Consejo Superior de Investigaciones Científicas, 1962.

MiLTON, John. English poems edited with life, introduction and selected notes by R.C. Browne. Oxford: Clarendon Press, 1878.

Muratori, Lodovico Antonio. Opere di Lodovico Antonio Muratori. A cura di Giorgio Falco e Fiorenzo Forti. Milano-Napoli: Riccardo Ricciardi Editore, 1964.

Naveros SÁnchez, Juan. El fundador de la Real Academia de Córdoba: D. Manuel María de Arjona y Cubas, 1771-1820. Córdoba: Real Academia de Ciencias, Bellas Letras y Nobles Artes de Córdoba, 1991.

NERLICH, Michael. Untersuchungen zur Theorie des klassizistischen Epos in Spanien (1700-1850). Genève \& Paris: Droz, 1964.

OlaY VAlDÉs, Rodrigo. "La poesía y sus constitutivos esenciales según Feijoo». Cuadernos Dieciochistas, 2015, 16, pp. 339-369.

PeErS, E. Allison. «Milton in Spain». Studies in Philology, 1926, 23, pp. 169-183.

Pegenaute, Luis. «La recepción de Milton en la España ilustrada: visiones de El Paraíso Perdido». En La traducción en España (1750-1830): lengua, literatura, cultura. Lleida: Universitat de Lleida, 1999, pp. 321-334.

PIERCE, Frank. "The canto épico of the Seventeenth and Eighteenth Centuries». Hispanic Review, 1947, 15, pp. 1-47.

Pope, Alexander. The Iliad of Homer. London: Charles Rivington, 1760.

Pozuelo Yvancos, José María. «Teoría del Canon». En Pozuelo Yvancos, José María y ARADRA SÁNCHEZ, Rosa María. Teoría del canon y literatura española. Madrid: Cátedra, 2000, pp. 15-140.

RAABE, Paul. "Die Zeitschrift als Medium der Aufklärung». Wolfenbüttler Studien zur Aufklärung, 1974, I, pp. 99-112. 
Ricoeur, Paul. Caminos del reconocimiento. Trad. Agustín Neira. México D.F.: Fondo de Cultura Económica, 2006, pp. 120-125.

RodríGuez SÁNCHEZ DE LEÓN, María José. "La pugna entre antiguos y modernos en el periodo de entre siglos: del canon y lo clásico». En GaviÑo RodríGuez, Victoriano y DuRáN LÓPEZ, Fernando (eds.). Gramática, canon e historia literaria. Estudios de filología española entre 1750 y 1850. Madrid: Visor Libros, 2010, pp. 373-396.

RODRíGUEZ SÁNCHEZ DE LEÓN, María José. «Verosimilitud literaria y experiencia estética en la Ilustración». eHumanista, 2014, 27, pp. 52-62.

Rodríguez SÁNCHEZ DE LEÓN, María José. «El conocimiento científico y la comprensión hermenéutica y crítica de la literatura: la propuesta de Juan Andrés». En RODRÍGuEz SÁNCHEZ de LeÓn, María José y Amores Fúster, Miguel (eds.). La ciencia literaria en tiempos de Juan Andrés (1740-1817). Madrid: Visor Libros, 2019, pp. 125-149.

RolLi, Paul. Examen de l'Essai de M. de Voltaire sur la poesie epique. Paris: Rollin Fils, 1728.

Romani, Bruno. La critica letteraria tra l'otto e il novecento. Roma: Gremese Editore, 1975, pp. 1-23.

SÁNCHEZ-BlanCO, Francisco. Europa y el pensamiento español del siglo XVIII. Madrid: Alianza, 1991.

TAnganelli, Paolo (ed.). La tela de Ariosto. El «Furioso» en España: traducción y recepción. Málaga: Universidad de Málaga, 2009.

Torralbo Caballero, Juan de Dios. «La recepción de Milton en España: el papel del humanismo ilustrado sevillanom. Alfinge, 2008, 20, pp. 151-170.

Torralbo Caballero, Juan de Dios. «Lista, Reinoso y Jovellanos: pioneros en la importación de poesía inglesa». En Blanco, María Pilar (ed.). El Cid y la Guerra de la Independencia: dos hitos en la historia de la traducción y la literatura. Madrid: Universidad Complutense, 2010, pp. 257-287.

Torralbo Caballero, Juan de Dios. «Jovellanos: traductor de poesía inglesa en Andalucía». Hikma, 2017, 16, pp. 112-131.

URZAINQUI, Inmaculada. «Un nuevo instrumento cultural: la prensa periódica». En ÁLVAREZ BARrientos, Joaquín; López, François y UrZAINQui, Inmaculada. La República de las Letras en la España del siglo XVIII. Madrid: Consejo Superior de Investigaciones Científicas, 1995, pp. 125-216.

URZAINQUI, Inmaculada. "La crítica literaria en la prensa del siglo XVIII, elementos de su discurso teórico». Bulletin hispanique, 2000, 102, 2, pp. 519-559.

URZAINQUi, Inmaculada. "La república periodística al filo del 800». En MORALES MOYA, Antonio (coord.). 1802, España entre dos siglos. Madrid: Sociedad Estatal de Conmemoraciones Culturales, 2003, pp. 321-350.

VegA, María José y Vilà, Lara (dirs.). La teoría de la épica en el siglo XVI (España, Francia, Italia y Portugal). Vigo: Academia del Hispanismo, 2010. 
